\title{
13. Respiration and Airway Management \\ What should be noted in anesthetic management of patients who require surgically achieved hemostasis after undergoing head and neck surgery?
}

\author{
Hiromi Kurokawa M.D., Miwako Nakao M.D. and Miyo Kimura M.D. \\ Hiroshima Prefectural Hospital 20 県立広島病院
}

Background and Goal of Study:

Head and neck surgery is associated with potential life-threatening risks, because the surgical site is close to the respiratory tract. Notably, postoperative bleeding can lead to a critical situation, thus anesthetic management should be performed very carefully for obtaining surgical hemostasis. To investigate perioperative events, we retrospectively reviewed the records of patients who underwent otolaryngology surgery and selected those who experienced post-surgical bleeding which require a procedure to obtain hemostasis under general anesthesia.

\section{Materials and Methods:}

The records of all patients who underwent otolaryngology surgery at our institution from 2008 to 2015 were assessed. We noted surgery details, postoperative hemorrhage incidence, time until re-operation, anesthetic methods, and postoperative management.

\section{Results and Discussion:}

The study population consisted of 4,812 patients (tonsillectomy 967, thyroid surgery 86, submandibular gland surgery 35, others 3,724). An additional surgical procedure under general anesthesia in order to obtain hemostasis was necessary in 13 cases $(0.3 \%)$, including $9(0.9 \%)$ following tonsillectomy, 3 (3.5\%) following thyroid surgery, and 1 (2.9\%) following submandibular gland surgery.

As for the time until re-operation, hemostasis was performed after few hours in 2 of the tonsillectomy cases, while that was done from 4 to 13 days after the operation in the other 7 due to secondary bleeding. In all thyroid surgery and submandibular surgery patients, hemostasis was achieved within 24 hours.

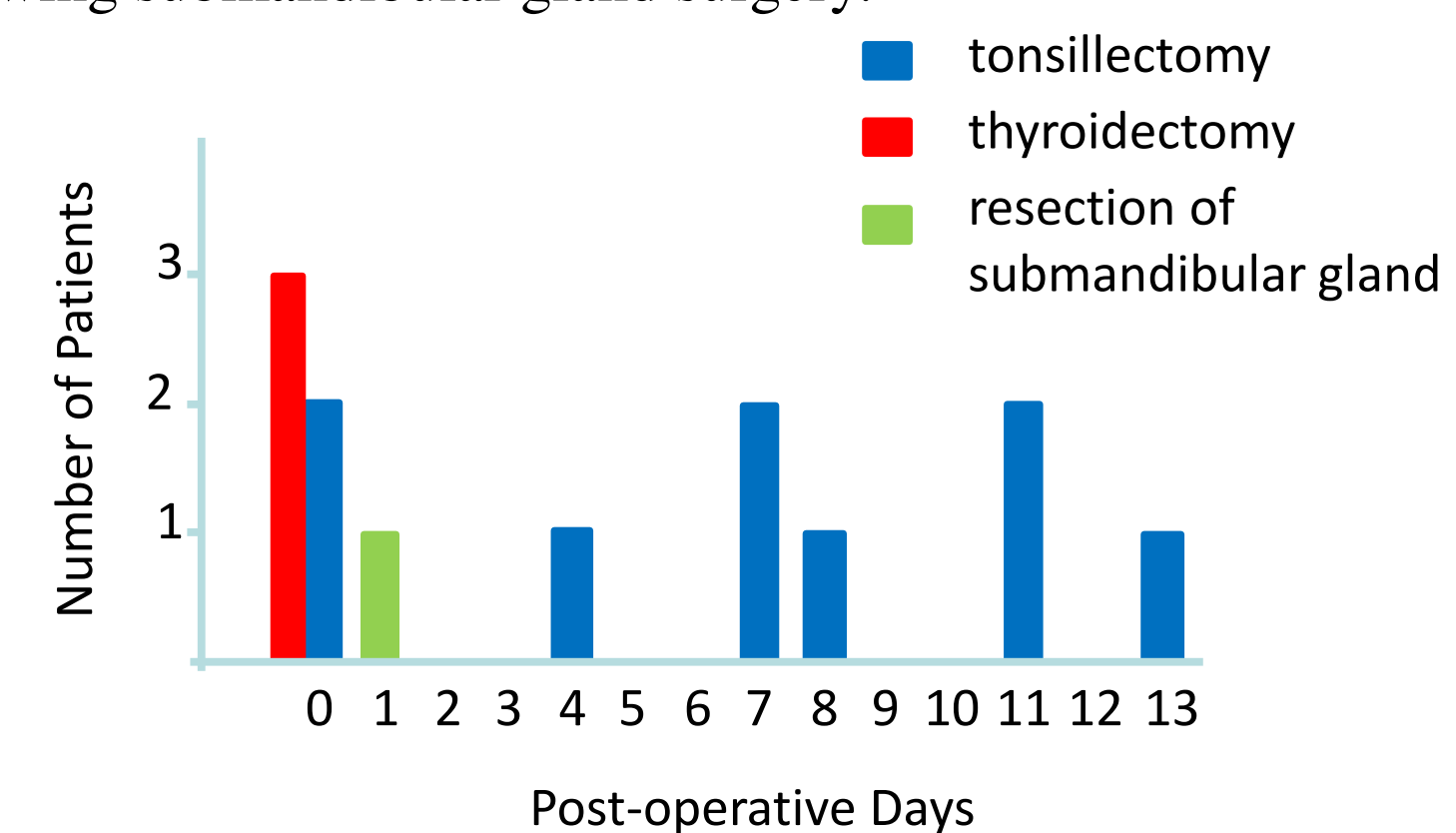

Post-operative Days

\begin{tabular}{|c|c|c|c|c|c|c|c|c|c|c|c|c|c|}
\hline & & & & & & \multicolumn{6}{|c|}{ Conditions of intubation } & \multirow{2}{*}{ tubation } & \multirow{2}{*}{\begin{tabular}{|} 
Length of \\
stay \\
in ICU (day)
\end{tabular}} \\
\hline $\begin{array}{c}\text { Patient } \\
\text { No. }\end{array}$ & Age & Primary operation & $\begin{array}{l}\text { Rebleed } \\
\text {-ing } \\
\text { period } \\
\text { POD }\end{array}$ & $\begin{array}{l}\text { In hospital } \\
\text { Or } \\
\text { discharged }\end{array}$ & CPA & $\begin{array}{l}\text { Semi awake } \\
\text { intubation }\end{array}$ & $\begin{array}{c}\text { Use of } \\
\text { Muscle relaxant }\end{array}$ & Intubation device & Difficulty & Trial & $\begin{array}{l}\text { Induction } \\
\text { time(min) }\end{array}$ & & \\
\hline 1 & 7 & tonsillectomy & 7 & discharged & & & - & laryngoscope & easy & 1 & 5 & + & - \\
\hline 2 & 61 & resection of submandibular gland & 1 & In hospital & & + & - & AWS $\rightarrow$ Fiber & difficult & 2 & 14 & - & 2 \\
\hline 3 & 63 & hemi-thyroidectomy & 0 & In hospital & + & 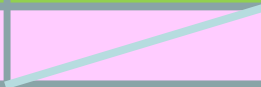 & - & AWS & difficult & 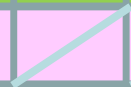 & 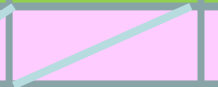 & - & 4 \\
\hline 4 & 67 & hemi-thyroidectomy & 0 & In hospital & & & - & AWS & easy & 1 & 6 & - & 2 \\
\hline 5 & 38 & tonsillectomy & 8 & discharged & & & + & laryngoscope & easy & 1 & 2 & + & - \\
\hline 6 & 7 & tonsillectomy & 7 & discharged & & & + & laryngoscope & easy & 1 & 8 & + & - \\
\hline 7 & 65 & hemi-thyroidectomy & 0 & In hospital & & + & - & AWS & easy & 1 & 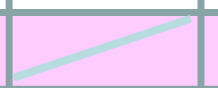 & - & 4 \\
\hline 8 & 17 & tonsillectomy & 4 & In hospital & & & $+\rightarrow-\rightarrow+$ & Fiber + laryngoscope $\rightarrow$ laryngoscope & difficult & 4 & 44 & - & 2 \\
\hline 9 & 16 & tonsillectomy & 11 & discharged & & & + & laryngoscope & easy & 1 & 3 & + & - \\
\hline 10 & 6 & tonsillectomy & 13 & discharged & & & + & laryngoscope & easy & 1 & 6 & + & - \\
\hline 11 & 51 & tonsillectomy & 11 & discharged & & + & - & laryngoscope & easy & 1 & 11 & - & 3 \\
\hline 12 & 29 & tonsillectomy & 0 & In hospital & & + & - & $M A C \rightarrow A W S \rightarrow$ Fiber + MAC & difficult & 3 & 17 & - & 2 \\
\hline 13 & 5 & tonsillectomy + adenoidectomy & 0 & In hospital & & & $-\rightarrow+$ & laryngoscope & moderate & 2 & 3 & - & 1 \\
\hline
\end{tabular}

CPA: cardiopulmonary arrest, AWS: airway scope, Fiber: fiberscope, MAC: McGrath

Regarding anesthesia in these cases, 2 thyroid surgery patients were intubated in the ward, indicating that a critical constriction had occurred in the upper respiratory tract with internal bleeding. 7 were intubated without the use of a muscle relaxant and 2 were intubated using a fiberscope. Some induction times were long in post-tonsillectomy bleeding (e.g. 17, 44min), which indicated external bleeding in the pharynx interfered with the view.

In addition, 8 patients were transferred to the ICU with a tracheal tube used to secure the airway.

\section{Conclusion:}

Airway narrowing caused by internal bleeding requires more rapid airway management for hemostasis in cases with bleeding following postthyroid surgery and post-submandibular surgery. In patients with external bleeding causing sight impairment, an appropriate method to secure the airway opening, such as that used for maintaining spontaneous breathing in post-tonsillectomy bleeding, is necessary. 